\title{
Depoimento sobre a Trajetória Artística e o Projeto "Alguidar: Uma Apropriação"
}

\author{
Posena Boroln
}

No depoimento aqui apresentado mostro a possibilidade do uso da técnica do torno como suporte de desenvolvimento de uma linguagem plástica. Assim sendo, passo a expor a minha visão de arte em relação ao trabalho artesanal dos oleiros da Grande Florianópolis, me aproprio daquela produção intencionalmente, objetivando descondicionar o olhar do espectador para objetos do cotidiano, possibilitando uma outra leitura dos mesmos.

A origem desta pesquisa se deu no decorrer das aulas de torno freqüentadas na Universidade do Estado de Santa Catarina, em 1996. A cada tentativa de centralização da argila na roda, surgia a inquietação e a curiosidade de saber e conhecer sobre a vida e a obra dos tradicionais oleiros; assim são chamados os artesões que trabalham com o torno, da região da Grande Florianópolis - SC.

Num primeiro momento foi realizada uma pesquisa de campo nas oficinas dos oleiros. Obteve-se informações por meio de entrevistas, levantamento de dados e trocas de experiências que buscavam conhecer o trabalho e a vida daquelas pessoas Uma vez feito este levantamento e constatado o risco de extinção deste oficio nesta região, busca-se resgatar o uso do torno como técnica em si, e assim colaborar na continuidade dos técnicos artesões que se utilizam do torno como profissão.

Numa etapa posterior busca-se relacionar o uso do torno dentro do contexto artístico contemporâneo 
através da apropriação e da descaracterização do utilitário feito no torno como forma de expressão artística individual.

A minha intenção na realização dos trabalhos plásticos que complementam esta pesquisa, foi a tentativa de descondicionar o olhar do espectador, em relação a um objeto do cotidiano. Intenção esta, de retirar algo que faz parte do folciore, da tradição e da cultura desta região, no caso as vasilhas feitas pelos oleiros, e transmutá-las para um outro ambiente, que não o delas, possibilitando uma nova versão visual.

A idéia era a de que o observador olhasse esses utilitários "com outros olhos", com uma visão que não fosse a do utilitário em si, e sim tentar sensibilizar para um olhar num plano em nível estético.

Assim sendo, proponho um resgate, ou seja, a revalorização das peças manufaturadas pelos oleiros, no sentido de transcodificá-las, transformando-as assim numa linguagern de expressão plástica. O objetivo da apropriação destas vasilhas é chamar a atenção do público, para uma técnica artesanal que está desaparecendo por várias razões, entre elas a falta de mão-de-obra qualificada.

Desta forma, para a realização do meu trabalho cerâmico, optei entre outras, por uma vasilha simples de uso genérico, o "Alguidar". Esta escolha foi feita devido a limpeza de sua forma, o que possibilitou que eu me apropriasse dela interferindo, colando, sobrepondo, incrustando, repetindo, etc., com a intenção de não poluir visualmente. Os resultados destas apropriações se deram, graças a um longo e trabalhoso caminho que foi percorrido com intensa dedicação, tanto na pesquisa das temáticas quanto na pesquisa dos materiais e soluções técnicas para estes. Para um melhor entendimento na leitura destes resultados, achei por bem traçar como ocorreu o meu processo de criação. 
O material pelo qual optei para representar a minha necessidade latente de me expressar plasticamente foi a argila. Esse material tão primitivo que nos remete a épocas tão remotas da história, possibilita através de suas qualidades plásticas inúmeras experiências formais.

A nobreza da matéria argila ao ser amolecida pela âgua e modificada, intuitiva ou racionalmente, pela mão humana que a toca e a sente como se fizesse parte do seu próprio corpo, provoca sutis, mas extremamente profundas, revelações de cunho muito intimo agindo misteriosamente num nível que a razão muitas vezes não tem alcance. Essas revelações se dão através das representações arquetipicas que se concretizam pelo toque, o amassar e o sentir daquele que da argila se apossa, gestando a cada momento novas materialidades.

Ao se revelarem as materialidades primeiras, o olhar nelas paira, nos fazendo pensar e refletir sobre 0 que elas próprias transmitem, qual é o seu sentido, o porque de estarem ali. Esse pensamento nos leva a uma compreensão de nós mesmos e da nossa função como criadores de novas materialidades, as quais conceitualizadas tomam um real objetivo perante a vida e funcionam como o verdadeiro sentido da arte. Ao captar e representar os mais profundos sentimentos e anseios da humanidade, o indivíduo transcende a sua pequenez e se intera com o cosmo comunicando-se através de sua obra.

Cada material por si só, já possui características e comportamentos individualizados, muitas vezes até, com uma linguagem bastante expressiva. O acúmulo de conhecimento, ou seja, o desenvolvimento de um pensamento através das informações depositadas na nossa memória, nos dá condições de realizar alterações nos materiais obtendo resultados, anteriormente imaginados ou não. 
Segundo Lúcia Pi, Coordenadora Cultural do Instituto de Idiomas Yazigi, o que estou fazendo é semelhante ao que Duchamp fazia nos seus "readymade", ou seja, o "descondicionamento do olhar através da construção de uma interferência no objeto em si".

Portanto, a partir do momento em que Duchamp em 1914 realiza o primeiro "ready-made", um portagarrafas metálico intitulado escultura, esclarece Restany (1979, p. 294), "a arte se toma um gesto moral que justifica todos os olhares novos ao mundo. Batizando como obra-de-arte um objeto de série, Marcel Duchamp afirmava a primazia da responsabilidade moral do artista. Mas descobria ao mesmo tempo, através do folclore técnico de sua época, o sentido autêntico da natureza humana, industrial e urbana".

Lúcia Pi, acrescenta ainda que o meu trabalho pode se caracterizar como uma "Meta-linguagem" no sentido que faço construção de uma obra a partir de uma outra obra já existente, no caso as peças dos oleiros, respeitando a "trama fundamental" que seria somente a interferência, sem a descaracterização da forma em si. Ou, em última análise, pode ser denominado um "new ready-made".

O processo de pesquisa das formas encontravase no inicio, surgiam inúmeras possibilidades de montagem e apresentação das mesmas. No decorrer do processo surge a preocupação pelas questões dimensionais, uma vez que as peças foram crescendo e tomando porte, causando problemas com as questões relacionadas a montagem, ao transporte e armazenagem das mesmas.

Os trabalhos que realizo não estão desvinculados dos questionamentos sobre a vida perante o todo; a família, o relacionamento à profissão, à espiritualidade e à própria morte. Acredito, seja uma maneira de autoconhecimento e auto-afirmação perante o mundo. A 
dialética dos opostos, é uma característica constante em todo o meu processo de criação, e aparece também na série dos alguidares, assim como a incrustação de pregos e o acréscimo de elementos que fazem parte da minha trajetória de vida.

Acredito que num âmbito mais profundo e a nível inconsciente, esteja trabalhando a própria personalidade. Talvez, tentando expulsar "pregos" do meu íntimo. A união das vasilhas nos remete a formas que já haviam aparecido em fases anteriores. Estas sugerem vértebras de peixes, medusas, etc., fazendo com que as formas marinhas, que apareciam em outras épocas, venham novamente à tona. As peças quando colocadas enfileiradas, se assemelham a colunas vertebrais, ou a totens.

A colocação dos pregos é um ato repetitivo como o trabalho da olaria, e a opção por unir estas peças, evidencia ainda mais esta ação. No trabalho plástico, a problemática da repetição é uma constante.

René Passeron classifica os vários tipos de repetição, dentre elas, e na qual classifiquei meu trabalho, define-se como repetição estrutural,

". ..uma repetição interna à própria obra, presente ao nível de sua estrutura e mais ou menos aparente para aquele que a recebe. A análise estrutural da obra, quando deixa transparecer mais ou menos deliberadamente efeitos repetitivos, abre-se à uma estética da repetição, estética ligada à concepção e previsão dos efeitos desejados de uma repetição instauradora. Como objeto específico de consumo afetivo, esta repetição tende a se despir." (trad. por) (Passeron (1989, p. 82).

As incrustações metálicas despertam o sentimento de agressividade e repulsa e através da sua colocação numa sequência ritmada de linhas 
perpendiculares, formadas pelos pregos que penetram as peças, dinamizam o olhar com seu contraste entre a argila e o metal.

Este efeito estético de força e ofensividade revelado pelo metal, tem a dualidade da fragilidade adquirida após a queima. Na construção das peças a argila é maleável e delicada, enquanto o metal é rígido e resistente. Após a transformação destes materiais através da ação do calor, os papéis são invertidos, a argila passa a ser a resistência, a força, e o metal a parte frágil e delicada. Ao mesmo tempo que a argila chama para o toque, os pregos nos expulsam pelo medo do ferimento que pode ser causado. É constante em mim a indagação da freqüente manifestação de repulsa que o trabalho causa nas pessoas e ao mesmo tempo a intrigante curiosidade ao toque. Muitas vezes os pregos são colocados de uma maneira muito compulsiva, num movimento manual bastante ritmado, até o limite da aceitação da peça e da própria mão dando a sensação de pêlos sobre a mesma, fazendo refletir sobre a dualidade da materialidade criada. Inicialmente este processo era todo feito pessoalmente, mas em determinado momento deixou de ter a devida importância e foi terceirizado. É muito evidente a preocupação com os contrastes, o dentro e o fora, o interior e o exterior, o positivo e o negativo, o aberto e o fechado, o Yin e o Yang, o masculino e o feminino, o côncavo e o convexo, etc. .

Sendo esta, uma fase pensada e elaborada a nível estético, os significados das obras muitas vezes só surgem posteriormeńte através da leitura de uma exposição montada. Os elementos acrescidos nas obras já são ricos de significado os quais são levados em consideração na própria manufatura das mesmas. Fazendo uma análise da minha trajetória, posso afirmar que eu me leio através do meu trabalho. E penso, que todo este caminho percorrido pela cerâmica está intimamente ligado ao caminho de crescimento 
pessoal, mesmo quando é desenvolvido a nível inconsciente. Para Campbell, o perfeito investigador dos mitos, naturalmente no caminho aberto por Jung, para a interpretação da alma, conclui que o centro da alma, de onde emana a energia psíquica, é o inconsciente, sendo uma ilusão a idéia de que a razão "comanda o espetáculo".

Durante os cinco anos de pesquisa sobre a temática dos alguidares (1996 a 2001), a preocupação sempre foi construir através da sua forma, as peças sempre eram acrescidas de outras e consequentemente tomavam escalas bastante consideráveis. Neste último ano houve a necessidade de um basta, constantemente surgia em meu pensamento alguns "flashes", relacionados com a desconstrução daquela forma tão pesquisada que acabou tornando-se exaustiva. Assim sendo, foi realizado um vídeo, onde mostra a desconstrução do alguidar através da água. A água vai tomando conta do interior da peça até transbordá-la e aos poucos desagregar as suas partículas de argila seca porém cruas. Cada partícula, quando absorvia a água, inchava e tomava um espaço fora da peça remetendo a própria terra erodida pela abundância de água. Quando foi finalizado este vídeo, acreditei que o processo dos alguidares tinha finalizado daquela forma, mas estava enganada. O processo não finalizou pela desconstrução através da água e sim pela desconstrução através do fogo. Algumas peças não estavam muito bem queimadas e resolvi ser cautelosa requeimando-as.

O forno que possuo não é automático, e encarreguei uma pessoa de desligá-lo em determinada temperatura; este fato não ocorreu. As peças foram submetidas a uma super exposição ao calor, resultando num bloco único após a fusão das mesmas. Não foi possível removê-las do forno separadamente, grudaram e deformaram 
completamente. A cor avermelhada transformou-se numa tonalidade azul esverdeada com partes petrificicadas. As peças que continham pregos em sua superfície, fundiram ainda mais, deixando riscos pretos em determinados pontos e massas de metal fundido em outros. Ficou muito interessante.

Assim entendi que o meu próximo trabalho a ser exposto deverá ser as duas desconstruções juntas dialogando, talvez até num entendimento, pois a disputa entre o excesso da ação da água e o excesso da ação do fogo é inútil. Cada um tem seu poder e suas particularidades, assim como na vida, cada ser tem que descobrir quais são seus excessos, para quem sabe controlá-los e viver melhor. Mais uma vez posso confirmar que a leitura que faço da minha vida está completamente registrada em meu trabalho plástico, mesmo que venha de forma acidental, basta estar atenta. Acredito na arte como um processo de revelações, auto-conhecimento.

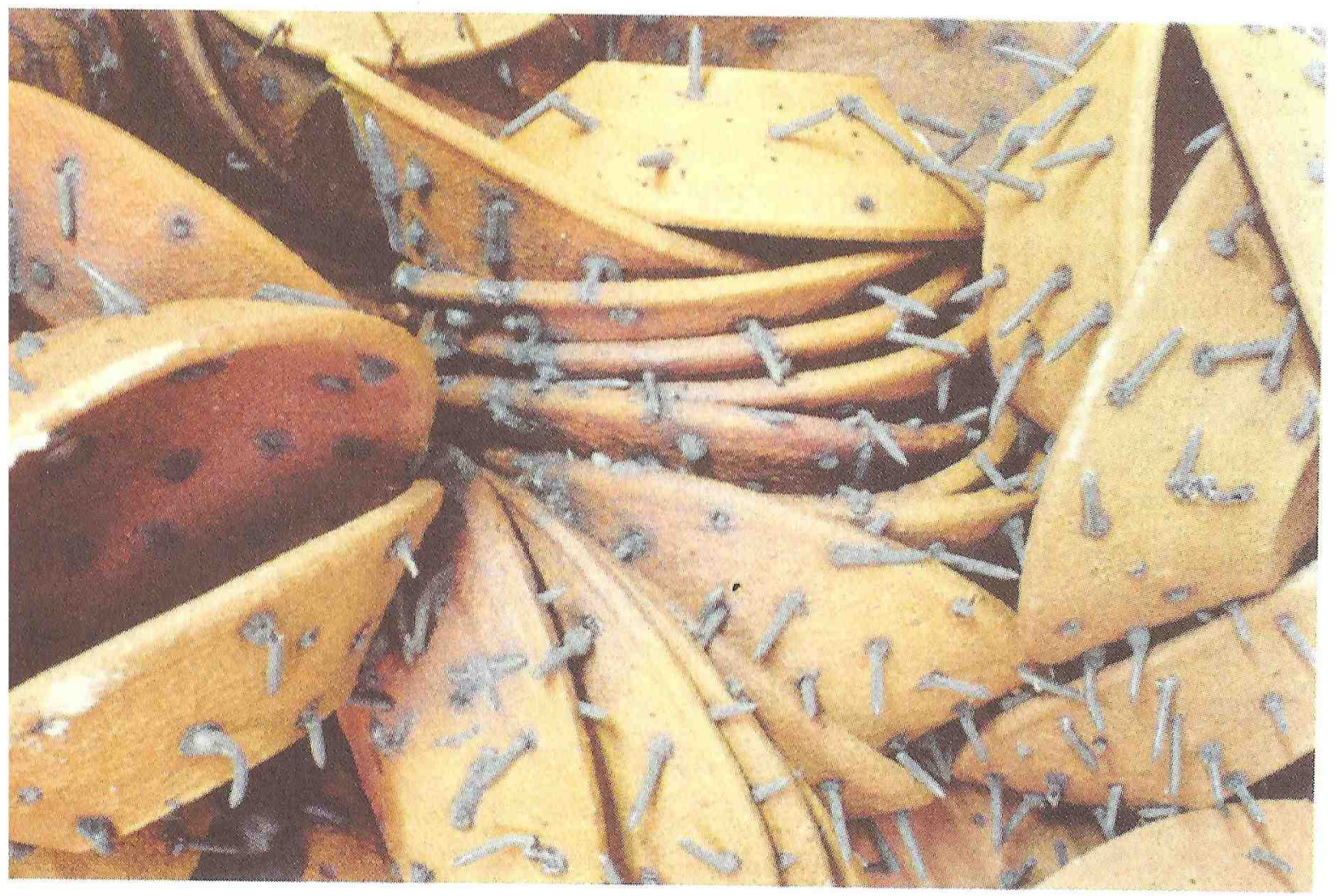




\section{Urnas Funerárias}

O trabalho aqui apresentado chama-se "Urnas Funerárias", consiste em doze Alguidares, os quais representam o ciclo anual dos doze meses. Internamente, estão cheios de carvão vegetal que remelem as cinzas e a putrefação, lembrando a decadência dos valores da raça humana. Sobre o carvão, em onze Alguidares, estão depositados ovos galados, referenciando o ciclo da vida, de onde se vem, e para onde se vai. Sobre o carvão, do décimo segundo Alguidar, estão incrustados pingentes de cristais, os quais são associados a luminosidade, esperança e vida. Os doze Alguidares estão apoiados sobre uma cama de pregos, elemento bastante representativo em meu trabalho plástico. A presença dos pregos, despertam em mim questionamentos referentes a agressividade de um modo geral. A cama de pregos é uma mandala, que novamente referencia os ciclos de evolução e involução da humanidade. A cor preta, representa a escuridão, os medos e as incertezas relacionadas a morte.

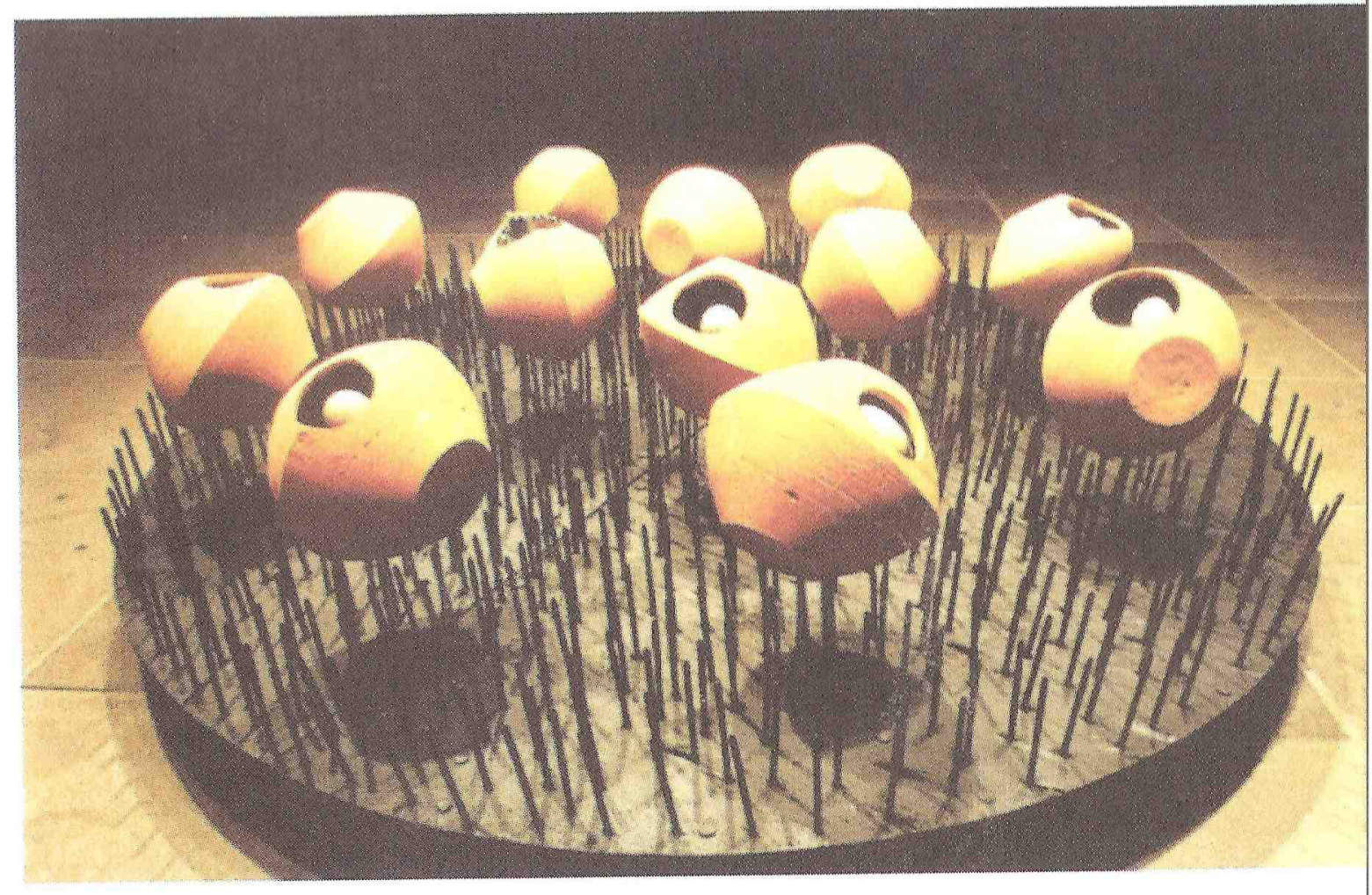




\section{Bocas Que Ouvem}

trabalho aqui exposto remete às questões voltadas aos discursos de um modo geral, tanto político, ideológico, religioso, como também acadêmico. É uma crítica a tudo aquilo que as pessoas ditam como verdades absolutas, dentro das prisões mentais geradas pelas suas próprias crenças.

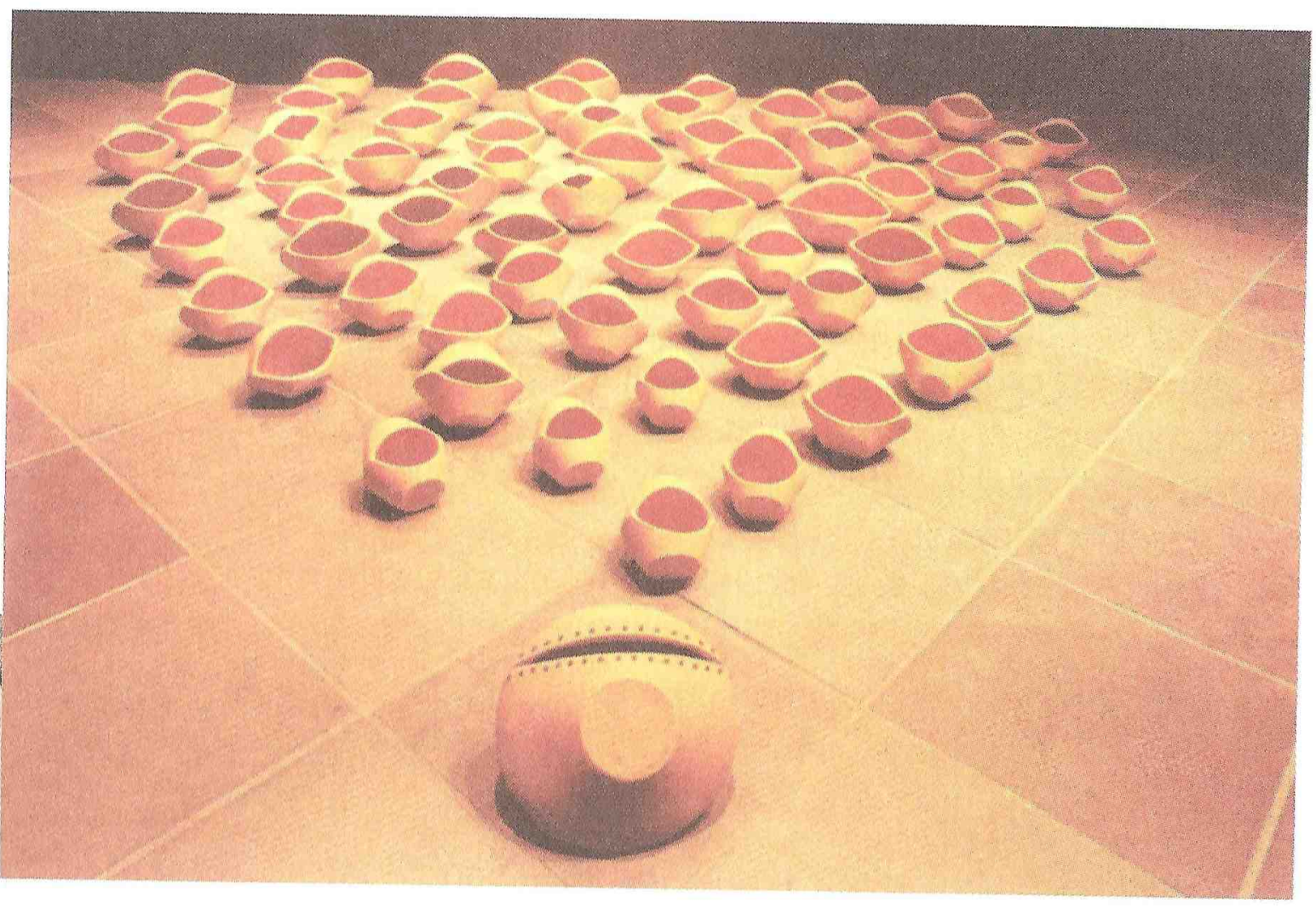

\section{PAX}

O trabalho aqui apresentado faz uma referência às questões voltadas à violência, não somente a violência fisica, mas a agressão generalizada, a violência gerada pelas verdades e necessidades que os seres humanos criaram, para superarem as suas próprias loucuras. Os cinco alguidares dispostos em forma de flores e conectados por mangueiras de plástico, estão recobertos parcialmente por pedaços de couro cravejados de cartuchos de revólver. 


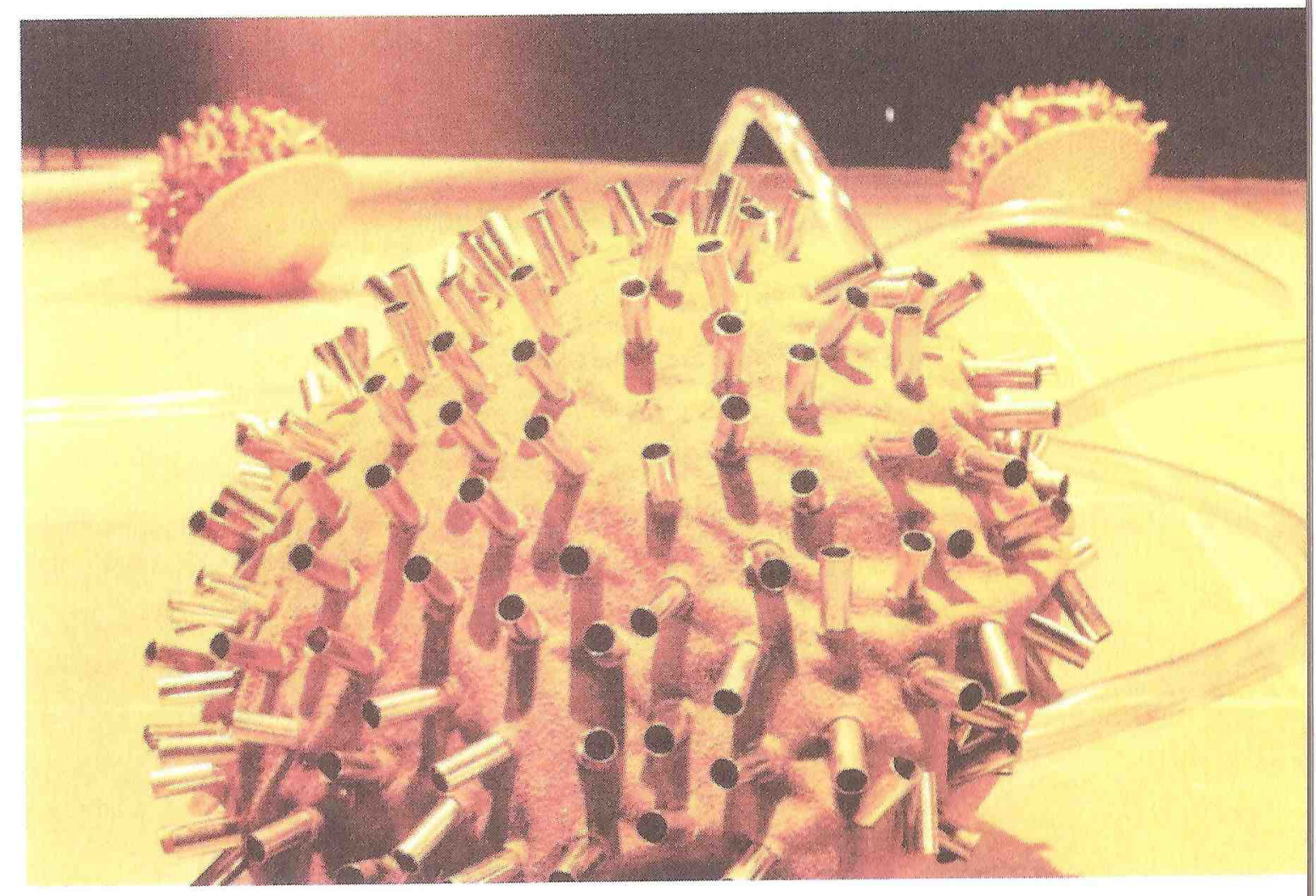

\section{Referências Bibliográficas}

PASSERON, René. Pour une Philosophie de la creation. Paris: Klincksiesck. 1989.

CAMPBELL, Joseph. O Poder do Mito. São Paulo: Palas Athena, 1990. 